\title{
The ABCD of GOLD made clear
}

\author{
Peter M.A. Calverley \\ Affiliation: Institute of Ageing and Chronic Disease, University of Liverpool, Dept of Clinical Sciences, \\ University Hospital Aintree, Liverpool, UK.
}

Correspondence: P.M.A. Calverley, Institute of Ageing and Chronic Disease, University of Liverpool, Dept of Clinical Sciences, University Hospital Aintree, Lower Lane, Liverpool, L9 7AL, UK.

E-mail: pmacalaliverpool.ac.uk

-

@ERSpublications

Data supporting the new GOLD COPD classification works but may lead to too rigid a segregation of patient groups http://ow.ly/nMoXn

Chronic obstructive pulmonary disease (COPD) remains a major public health problem. We know this with some certainty from the recently published Global Burden of Disease Study [1], a remarkable analysis of 235 causes of death in 21 regions of the world over a 30-year period. These data show that COPD will rise from the fourth most common cause of death in 1990 to the third by 2020. This gloomy prognostication fits with US data showing a progressive age-specific rise in mortality from COPD in both males and females over the last 50 years [2]. The challenge that COPD presents has been met by a dramatic increase in COPD-related research papers, which range from studies identifying airway loss in spirometrically mild disease [3], to improvements in case finding using the peak expiratory flows as screening tool [4], and to new antiinflammatory drugs and bronchodilators to diminish the symptom burden of this condition [5-7]. Marshalling this mass of information into a clinically useful format for patient care has fallen to those clinicians and methodologists who develop treatment guidelines and there is no shortage of these in the field of COPD. The first COPD guidelines were produced by both national and international societies with the joint American Thoracic Society (ATS)/European Respiratory Society (ERS) document [8] proving to be particularly influential. However, the rise of evidence-based medicine has had the unanticipated effect of decreasing the scope of guidance for COPD, which is now almost entirely focused on the relative merits of drug treatment as this is where the most robust clinical trial data are available [9].

One group, the Global Initiative for Chronic Obstructive Lung Disease (GOLD), has pursued a different track. This clinically led initiative arose from a National Heart, Lung, and Blood Institute (NHLBI)/World Health Organization (WHO) workshop reviewing the evidence about COPD care and, for more than 10 years, GOLD has provided relevant advice about the diagnosis and treatment of this condition. The GOLD group were amongst the first to try and stratify the strength of the evidence available for particular interventions, although the scheme they adopted would no longer be considered fit for purpose by methodologists using more elaborate systems to grade evidence. In an attempt to keep pace with the rapid accumulation of new data, the GOLD Science Committee adopted a novel approach for annual reviews of published data and modification of any of their previous recommendations while undertaking major reviews of the whole document in 2007 and 2011 [10]. The initial GOLD assessment system was linked to post-bronchodilator spirometry and this proved influential, not only in allowing researchers to categorise clinical data, but also in indicating where treatment might be initiated. However, it became increasingly obvious that the GOLD stages were being interpreted in too rigid a fashion, particularly as data became available showing that treatments initially restricted to one "stage" of the disease, showed benefits in others $[11,12]$. This led to a radical review of disease severity assessment and produced a new classification incorporating both symptom severity and the risk of adverse future events, as indicated by spirometry

Received: July 102013 | Accepted: July 302013

Conflict of interest: Disclosures can be found alongside the online version of this article at www.erj.ersjournals.com

Copyright @ERS 2013 
impairment and the likelihood of exacerbations being reported [10]. Needless to say, this change of focus had attracted much comment [13].

In this issue of the European Respiratory Journal (ERJ), some, but not all, of the members of the GOLD Science Committee have taken the opportunity to review four large observational studies published since the 2011 GOLD revision became available online [14]. Each of these studies addresses the distribution of COPD patients by the new classification and assigns them to the each of the four proposed quadrants: A: few symptoms, better lung function; B: more symptoms, better lung function; C: few symptoms, poor lung function; D: more symptoms, poor lung function. The GOLD authors provide a helpful summary of each study and then consider how the data generated provide insight into their new care mode. The result is a novel hybrid publication, in which published data are synthesised and then used as a basis for further debate. While other studies of this COPD classification have been published [15], the four papers discussed here are commendably broad including over 16000 COPD patients derived from a number of sources ranging from population surveys to specialist clinical services [16-19]. The authors of the ERJ article are generally familiar with the data they discuss as almost all of them have participated in one or more of these large clinical studies, thereby creating an iterative loop of ideas that can be hard to unravel. However, it does appear that the initial proposal for the four quadrant separation preceded the data analyses which were subsequently published and, thus, provide a legitimate test of the validity of the GOLD approach.

Several points emerge from these comparisons. The relative proportion of patients in each quadrant varies with the majority of individuals identified by population screening falling into group A, whilst in the other studies, where there is a larger input from hospital practice, patients are approximately equally divided between groups A and D with smaller numbers in B and C. As expected, this classification, based on the history of exacerbations, predicts future exacerbation risk, at least at a population level. However, it is worth recalling that $>25 \%$ of the individuals in the study by HURST et al. [20] changed their exacerbation frequency year on year, which may make it harder to apply the GOLD system with complete confidence and helps to explain some of the variability in quadrants B and C in the study by AGUSTI et al. [16]. Relatively few patients were assigned to groups $\mathrm{C}$ and $\mathrm{D}$, purely due to a history of frequent exacerbations and, in practice, spirometric impairment was the major determinant of this classification. The reviewed studies adopted somewhat different approaches to determine symptom intensity with one back calculating an estimated COPD assessment test (CAT) score from their health status data [17]. This further complicates the problems previously noted between the CAT score and the Medical Research Council grade, which the most recent online update of the GOLD statement has tried to address [21]. Contrary to expectations, patients in group B had a prognosis similar to those in group C, which rather challenges the idea of these patients being "low risk". Indeed, at a group level, spirometry rather than exacerbation history remains the principal determinant of prognosis.

Pooling the four large studies has allowed AGUSTI et al. [14] to answer several of the recurring questions about this new assessment approach. They make an understandable plea to apply this clinically based algorithm to data collected in future treatment trials. This would allow them to allocate treatment recommendations in a more "evidence-based" way than is currently open to them. However, it is encouraging to see that their first choice option for drug management largely correspond with the more robustly evidence-based approach developed by the UK National Institute for Clinical Excellence [22]. One word of caution is merited. In the published version of the GOLD diagram [10] a dotted line separates the quadrants and this was a deliberate decision, intended to suggest that the boundary between them is a relatively porous one. It would be a pity if the problems created by an overly rigid interpretation of an arbitrary forced expiratory volume in $1 \mathrm{~s}$ threshold in the earlier GOLD documents were now replaced by two equality arbitrary thresholds in the new one. Helpful as these approaches are to researchers classifying populations of patients, individuals lie in a spectrum of response and both spirometric impairment and symptom intensity are continuous variables rather than binary ones.

Nonetheless, the GOLD group are to be congratulated on their courage in leading our thinking about COPD, rather than adopting the more traditional role of treatment guidelines, which is to summarise in a rather conservative fashion available evidence. This move from guideline to management strategy is reflected in the re-titling of the GOLD documents and raises one other question which is bound to be frequently asked, namely, how widely are these recommendations going to be adopted and will they translate into a different pattern of patient care? The next few years should provide us with an answer to these important questions.

\section{References}

1 Lozano R, Naghavi M, Foreman K, et al. Global and regional mortality from 235 causes of death for 20 age groups in 1990 and 2010: a systematic analysis for the Global Burden of Disease Study 2010. Lancet 2012; 380: 2095-2128. 
2 Thun MJ, Carter BD, Feskanich D, et al. 50-year trends in smoking-related mortality in the United States. $N$ Engl J Med 2013; 368: 351-364.

3 McDonough JE, Yuan R, Suzuki M, et al. Small-airway obstruction and emphysema in chronic obstructive pulmonary disease. N Engl J Med 2011; 365: 1567-1575.

4 Jithoo A, Enright PL, Burney P, et al. Case-finding options for COPD: results from the Burden of Obstructive Lung Disease study. Eur Respir J 2013; 41: 548-555.

5 Jones PW, Singh D, Bateman ED, et al. Efficacy and safety of twice-daily aclidinium bromide in COPD patients: the ATTAIN study. Eur Respir J 2012; 40: 830-836.

6 Bateman ED, Rabe KF, Calverley PM, et al. Roflumilast with long-acting $\beta_{2}$-agonists for COPD: influence of exacerbation history. Eur Respir J 2011; 38: 553-560.

7 Dransfield MT, Bourbeau J, Jones PW, et al. Once-daily inhaled fluticasone furoate and vilanterol versus vilanterol only for prevention of exacerbations of COPD: two replicate double-blind, parallel-group, randomised controlled trials. Lancet Respir Med 2013; 1: 210-223.

8 Celli BR, MacNee W, ATS/ERS Task Force. Standards for the diagnosis and treatment of patients with COPD: a summary of the ATS/ERS position paper. Eur Respir J 2004; 23: 932-946.

9 Qaseem A, Wilt TJ, Weinberger SE, et al. Diagnosis and management of stable chronic obstructive pulmonary disease: a clinical practice guideline update from the American College of Physicians, American College of Chest Physicians, American Thoracic Society, and European Respiratory Society. Ann Intern Med 2011; 155: 179-191.

10 Vestbo J, Hurd SS, Agusti AG, et al. Global strategy for the diagnosis, management, and prevention of chronic obstructive pulmonary disease: GOLD executive summary. Am J Respir Crit Care Med 2013; 187: 347-365.

11 Jenkins CR, Jones PW, Calverley PM, et al. Efficacy of salmeterol/fluticasone propionate by GOLD stage of chronic obstructive pulmonary disease: analysis from the randomised, placebo-controlled TORCH study. Respir Res 2009; 10: 59.

12 Decramer M, Celli B, Kesten S, et al. Effect of tiotropium on outcomes in patients with moderate chronic obstructive pulmonary disease (UPLIFT): a prespecified subgroup analysis of a randomised controlled trial. Lancet 2009; 374: 1171-1178.

13 Rabe KF, Cooper CB. Global Initiative on Obstructive Lung Disease revised: what constitutes a guideline? Am J Respir Crit Care Med 2013; 187: 1035-1036.

14 Agusti A, Hurd S, Jones P, et al. FAQs about the GOLD 2011 assessment proposal of COPD: a comparative analysis of four different cohorts. Eur Respir J 2013; 42: 1391-1401.

15 Johannessen A, Nilsen RM, Storebo M, et al. Comparison of 2011 and 2007 global initiative for chronic obstructive lung disease guidelines for predicting mortality and hospitalization. Am J Respir Crit Care Med 2013; 188: 51-59.

16 Agusti A, Edwards LD, Celli B, et al. Characteristics, stability and outcomes of the 2011 GOLD COPD groups in the ECLIPSE cohort. Eur Respir J 2013; 42: 636-646.

17 Han MK, Muellerova H, Curran-Everett D, et al. GOLD 2011 disease severity classification in COPDGene: a prospective cohort study. Lancet Respir Med 2013; 1: 43-50.

18 Soriano JB, Alfageme I, Almagro P, et al. Distribution and prognostic validity of the new global initiative for chronic obstructive lung disease grading classification. Chest 2013; 143: 694-702.

19 Lange P, Marott JL, Vestbo J, et al. Prediction of the clinical course of chronic obstructive pulmonary disease, using the new GOLD classification: a study of the general population. Am J Respir Crit Care Med 2012; 186: 975-981.

20 Hurst JR, Vestbo J, Anzueto A, et al. Susceptibility to exacerbation in chronic obstructive pulmonary disease. N Engl J Med 2010; 363: 1128-1138.

21 Jones PW, Adamek L, Nadeau G, et al. Comparisons of health status scores with MRC grades in COPD: implications for the new GOLD 2011 classification. Eur Respir J 2013; 42: 647-654.

22 O’Reilly J, Jones MM, Parnham J, et al. Management of stable chronic obstructive pulmonary disease in primary and secondary care: summary of updated NICE guidance. BMJ 2010; 340: c3134. 